\title{
MICROBIAL COMMUNITY ANALYSIS IN ANAEROBIC PALM OIL MILL EFFLUENT (POME) WASTEWATER BY DENATURING GRADIENT GEL ELECTROPHORESIS (DGGE)
}

\author{
Husna Ahmad Tajuddin ${ }^{1}$, Luqman Chuah Abdullah², Thomas S.Y.Choong ${ }^{3}$ \\ ${ }^{I}$ Department of Chemical and Environmental Engineering,Faculty of Engineering,Universiti Putra Malaysia,43400 \\ UPM Serdang, Selangor, Malaysia \\ ${ }^{2}$ Department of Chemical and Environmental Engineering,Faculty of Engineering,Universiti Putra Malaysia, 43400 \\ UPM Serdang, Selangor, Malaysia \& Institute of Tropical Forestry and Forest Products (INTROP), Universiti Putra \\ Malaysia,43400 UPM Serdang, Selangor, Malaysia \\ ${ }^{3}$ Department of Chemical and Environmental Engineering,Faculty of Engineering,Universiti Putra Malaysia, 43400 \\ UPM Serdang, Selangor, Malaysia
}

\begin{abstract}
Microorganisms play a key role in wastewater bio-treatment processes and understanding the microbial community structure is of great importance to improve treatment performance. Denaturing gradient gel electrophoresis (DGGE) was used to monitor succession of the microbial community and thus predominant bands were sequenced to reveal the microbial community composition inside palm oil mill effluent (POME) wastewater.DNA bands from DGGE gels were excised with a sterile blade and placed in $1.5 \mathrm{ml}$ eppendorf tube containing $50 \mu \mathrm{l}$ deionized water $\left(\mathrm{ddH}_{2} \mathrm{O}\right)$. Tubes were incubated overnight at $4{ }^{\circ} \mathrm{C}$ to elute the DNA. Eluted DNA was purified using QIAquick gel extraction kits (QIAGEN, Inc., Valencia, CA) and was frozen and thawed three times.Microbial DNA successfully excised and purified from DGGE was amplified using polymerase chain reaction $(P C R)$.Five micro liters of the supernatant were used as a template to re-amplify the DNA using 16 s rDNA primers, $341 f$ (with no GC-clamp) (5'- cct-acg-gga-ggc-agc-ag-3') and reverse(r) primers $907 r$ (5'-ccc-cgt-caa-ttc-att-tga-gtt-t-3'). Amplification was repeated referring to the steps in 'PCR amplification of $16 \mathrm{~s} r D N A$ '. PCR products from agarose gels were cut and purified using QIAquick Gel Extraction Kit (QIAGEN, Inc., Valencia, CA), which were similar to the purification steps after recovery of DNA from DGGE, and sequenced in both directions with the same primers (with no GC-clamp) as used in PCR. Moreover, start-up is an important step in establishing proper community structure in all kinds of biological treatment processes. In anaerobic POME wastewater, 6 sequences of Firmicutes, 5 sequence of Proteobacterium and 2 sequences of Bacteroidetes were found through denaturing gradient gel electrophoresis (DGGE) results. Sequence closely related to Rummeliibacillus suwonensis strain G20 was detected grows at band BE10, BE11, BE12, BE15, BE16, BE17 and BE18. Meanwhile BE25 and BE26 were found at band after treatment process done.Rummeliibacillus suwonensis is an aerobic, Gram-positive, rod shaped, round-spore-forming bacteria which were isolated from aerobic condition.
\end{abstract}

Keywords: Palm oil mill effluent (POME), anaerobic POME, Denaturing gradient gel electrophoresis (DGGE), and microbial community.

\section{INTRODUCTION}

According to several studies, molecular biological methods give a more accurate view of microbial communities than culture-based methods alone [1]. Data of treatment performance and information of the microbes during this period is essential for revealing the correlation between contaminant removal and microbial community. Poor understanding of the response of microbial communities to sudden changes in organic and hydraulic loads is one of the major reasons for the inability to prevent operational instabilities in anaerobic reactors. Since there was a lack of study concerning the microorganisms involved in such processes, investigation of the microbial community during the treatment period was conducted. The knowledge of the microbial ecology involved in wastewater treatment becomes relevant for the control and efficiency of treatment since it allows for the evaluation of the microorganism interaction with the environment and other organisms. Scientifically, the capabilities of molecular methods to shed light on how microbial communities function will continue to expand and generate much larger quantities of key to success in achieving better design of the reactor operation and control. This study intends to fill the existing knowledge gaps whereby data of sequencing POME wastewater treatment performance and information of the microbes during his period is essential for revealing the correlation between contaminants removal and microbial community. From an applied science perspective, a researcher has to understand that we have already moved from old-way monitoring techniques to bio-monitoring procedures of anaerobic digestion processes using molecular techniques. 
The introduction of effluent discharge standards from the government has led to an increase in research on how to economically handle the significant volume of waste produced by the palm oil industry and mitigate the secondary and tertiary effects wastes have on the environment. Among these research efforts is reducing water pollution and managing bacterial populations that result from the high levels of oil and fatty acids in POME. Table-1 lists the properties of biologically treated POME (see Saifuddin and Dinara [2] for further listings).

Table-1: Properties of biologically treated POME [2].

\begin{tabular}{|l|c|c|}
\hline \multicolumn{1}{|c|}{ Property } & Values & $\begin{array}{c}\text { Standard } \\
\text { Discharge } \\
\text { Limits }\end{array}$ \\
\hline $\mathrm{pH}$ & 8.4 & $5-9$ \\
\hline Color & 9900 & - \\
\hline $\begin{array}{l}\text { Total Suspended Solid } \\
\text { (TSS) }\end{array}$ & 1800 & 400 \\
\hline $\begin{array}{l}\text { Chemical Oxygen Demand } \\
\text { (COD) }\end{array}$ & 4700 & 100 \\
\hline $\begin{array}{l}\text { Biochemical oxygen } \\
\text { demand }\end{array}$ (BOD) & 1350 & \\
\hline
\end{tabular}

*All units are in $\mathrm{mg} / \mathrm{l}$ except for $\mathrm{pH}$

Each ton of fresh fruit bunches processed in a standard palm oil mill creates 1 ton of liquid waste. This waste contains 27 $\mathrm{kg}$, of biochemical oxygen demand, $62 \mathrm{~kg}$ of chemical oxygen demand, $35 \mathrm{~kg}$ of oil and $6 \mathrm{~kg}$ of grease. This exceeds the BOD and COD of municipal sewage by more than 100 fold.

\subsection{Microbial Community}

Microorganism colonies play a significant role in wastewater treatment. Understanding their community structure is necessary to optimize treatment performance. Data on treatment performance in the wastewater treatment process and information on the microorganism colonies indicate provide insight to how contaminant removal is unfolding [3]. The positive role that microbial communities play in the treatment process indicates that the use of natural coagulants to improve sedimentation is desirable since they do not harm microbial communities in the way that chemical and metal salt coagulants do. Stability, sustainability and productivity of ecosystems are dependent upon diverse microbial communities [4].

Better reactor operation and control of its processes during the transition phase is rooted in knowing the structure of microbial communities living within the reactor ecosystem. How organic and hydraulic shocks affect reactor performance has been well studies for a variety of reactor configurations [5, 6, 7, and 8]. But not so much is known yet about the linkage between shocks and changes in microbial community structure. For example, they have been observed to change without discernable impact to reactor performance [9]. In other cases, microbial communities experienced shock load but their DGGE profile showed very little change [10]. At other times such shocks did result in different community structure [7, and 11]. Interestingly, Fernandez et al. [12] observed that a flexible microbial community structure in a reactor showed a better capability to withstand shock load than one having a stable community structure.

\subsection{PCR DGGE}

DNA is the molecular coding mechanism for transmitting genetic data from parent to offspring or from cell to subdivided cell. They contain the blueprint that enables all life forms on Earth to continue to exist. DNA are comprised of nucleotides made up by a sugar (deoxyribose), one of four bases, and a phosphate. These bases are cytosine (C), thymine $(\mathrm{T})$, adenine $(\mathrm{A})$, guanine $(\mathrm{G})$. The arrangement of a series of nucleotides results in different instructions for protein activity that underlies all organic function. The nucleotides arrange themselves into a molecular double helix chain commonly referred to as a DNA strand. The recombination of DNA during cellular division and reproduction introduces natural diversity to organisms and miscoding errors occur naturally (but relatively rarely) and are called mutations - which further add diversity to a population or species and enable it to adapt to an ever changing environment. Understanding mutations in microbial communities at the genetic level providessignificant insight to their function and community structure in wastewater. Given the important role that microbes playin wastewater treatment discussed earlier, genetic analysis can shed light on what microbes are coexisting and how to optimize acclimatized consortia.

Polymerase Chain Reaction-Denaturing Gradient Gel Electrophoresis (PCR-DGGE) is a technique for genetic fingerprinting and allows researchers to monitor microbial populations from wastewater samples (among other sources). DGGE, in fact, has revolutionized assessing microbial populations. Major bacterial species may be catalogued and their mutations noted and an overall phylogenetic tree constructed for bacteria found in the process. PCR products unfortunately result in a single DNA band that by itself is non-descriptive. DGGE overcomes this problem by separating bands based on nucleotide sequence differences as a result of the denaturing characteristics in the gel to which the DNA sample reacts. The bands that result in the gel theoretically represent a different bacterial population found within the sample. These "genetic fingerprints" can be cross-checked via existing genetic databases to explore microbial structural differences within a species and in comparison to other species. An example of this is shown in Fig-1. 


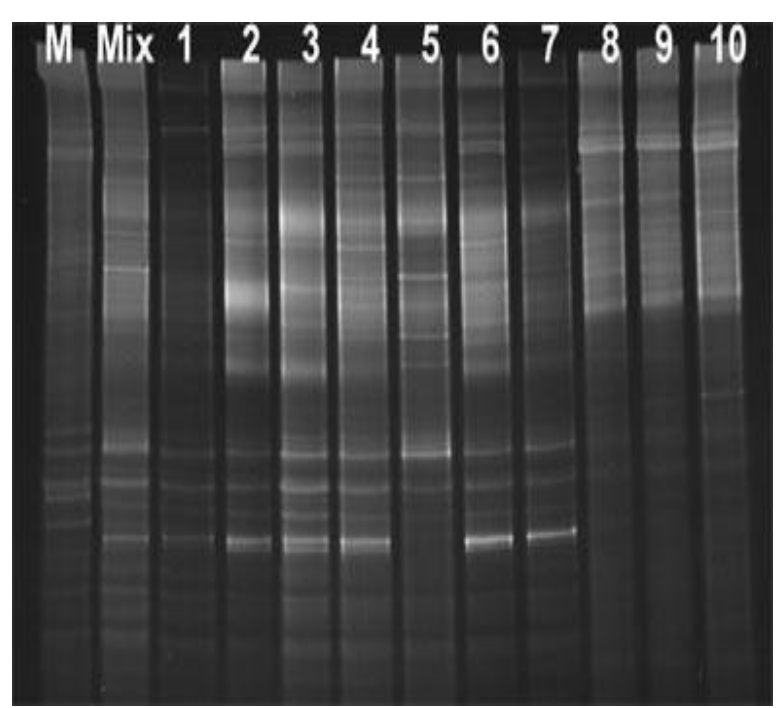

Fig-1: An example of a DGGE gel showing band compositions of various populations' samples, representative of complex microbial ecosystems. Each band in each lane represents a $16 \mathrm{~S}$ amplified product migrating to a unique position in the gel, which melts in a sequence dependant manner.

\subsection{Denaturing Gradient Gel Electrophoresis} (DGGE)

DGGE is used to separate DNA fragments through PCR amplification. This is achieved by taking advantage of the difference in stability of bonds for G-C pairing (which has three hydrogen bonds) and A-T pairing (which has two hydrogen bonds). DNA fragments reveal their genetic coding when electrophoresed in acrylamide gel that contains DNA denaturants. The difference in stability results in GC remaining double-stranded further up the gel than A-T pairings. Different sequences are seen according to where they unwound in the gel. This separation is facilitated by adding a short sequence of G's and C's, called a GC-clamp, and is attached to one end of the amplified DNA under examination.

This method provides the ability to profile microbial communities and monitor changes in them as the wastewater in which they inhabit undergoes different treatments. PCRDGGE is flexible enough to allow a combination of approaches to accurately identify, for example, the functional genes within specific bacterial populations. For microbial populations in wastewater being monitored, mutated and wild sequences may be distinguished without any prior knowledge of what these sequences are within closely related organisms.

\subsection{Mixed Culture}

Mixing pure well characterized cultures together has become a recent trend [13, and 14]. These co-cultures with their mixed populations have an edge functionally over pure cultures because higher degrees of biodegradation and mineralization are possible. This is achieved through the mixed culture's combined and complementary metabolic activities [15]. The disadvantages or a weakness of one pure culture is overcome by the other culture(s) strengths and vice versa.

Although mixed cultures provide benefit over pure cultures, acclimatized consortia have even more benefit. They are an enriched microbial community created by the repeated transfer of a native microbial community. Strains of microbes may have functional or dormant populations which provided diversity needed for slow adaptation of the community that stably delivers the desired metabolic process [16]. Furthermore, acclimatized consortia are stronger populations than mixed cultures because they contain natural adaptation due to their inherent diversity and tend to be tolerant toward each other [17]. Community succession in bacterial adaptation results in stable consortium development [18]. Additionally, efficient acclimatized consortia can be a potential source of individual efficient strains [19].

\subsection{Culturing Techniques}

Culturing and isolating microorganisms was carried out as a part of this study. After the activated sludge was acclimatized in the sample, the surviving bacteria was cultured and isolated for microorganisms' identification purpose. Microorganisms must have a constant nutrient supply if they are to survive. When attempting to grow microbes in the lab, adequate nutrition must be provided using artificial media. Nutrient agar $\left(\right.$ Difco $\left.^{\mathrm{TM}}\right)$ and broth (LabM) were used as a media and nutrient supply for bacteria to grow.

\section{MATERIALS AND METHODS}

An activated sludge sample was taken from an anaerobic pond at Serting Hilir, Serting, Negeri Sembilan treatment plant. The sample was kept in the clean container and kept in a cold room. All the glassware was cleaned and dried before sterilizing it in an autoclave. Then, all the glassware was placed into the autoclave. The autoclave was set at $121^{\circ} \mathrm{C}$ for 15 minutes under a normal setting. Lamina flow sterilized either with ethanol or ultraviolet light before engaging with microorganisms to avoid any contamination.

\subsection{Preparation of Nutrient Agar}

$23 \mathrm{~g}$ of nutrient agar powder (Difco ${ }^{\mathrm{TM}}$ ) was weighed and diluted in $1 \mathrm{~L}$ of distilled water. It was heated with frequent agitation and boiled until dissolved in the mixture. The mixture was autoclaved at $121^{\circ} \mathrm{C}$ for 15 minutes and while waiting for the agar, the bottoms of the sterile Petri plates were labeled with the source of the culture. Then, the mixture was cooled to $60^{\circ} \mathrm{C}$. After that, the agar was poured on Petri dish for half of the dish and left in the laminar flow to set overnight. The agars were kept in the laboratory's chillers for up to one month. 


\subsection{Streak Plate Technique (Superficial Dispersions}

\section{by Drigalsky's Technique)}

The spread plate technique is one of available techniques used to culture microbes that grow in activated sludge. In this experiment, this technique was applied to find out the species of microorganisms available in the sample. First, distilled water was transferred into cell tube with an amount of $9.9 \mathrm{ml}$ and then $0.1 \mathrm{ml}$ of the sample activated sludge was pipetted into the same cell tube. The mixture was mixed. These steps were done near the fire. Then, with same amount of sample $(0.1 \mathrm{ml})$ was pipette into the second cell tube. These steps were repeated several times as shown in Fig-2.

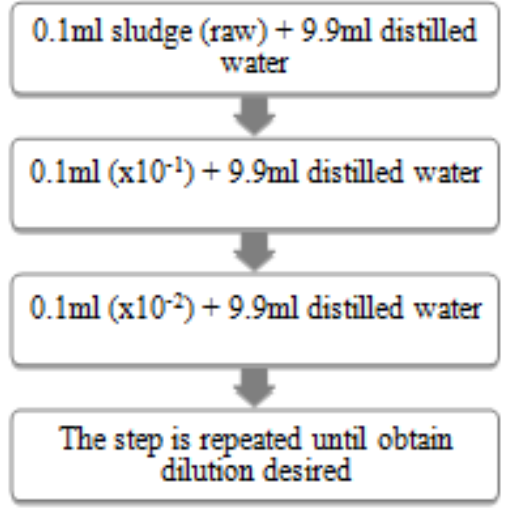

Fig-2: Dilution technique

The diluate is the liquid to be diluted and the diluent is what is used to dilute it. A dilution is defined by Eq. 1 and 2:

$\frac{\text { Volume of diluate }}{\begin{array}{c}\text { (Volume of diluate }+ \\ \text { volume of diluent) }\end{array}}=\frac{\text { Volume of diluate }}{\text { Total volume of solution }}$

For example, if adding $9 \mathrm{ml}$ of saline (diluent) to $1 \mathrm{ml}$ of culture (diluate), this gives a 1/10 dilution:

$\frac{1 \mathrm{~mL} \text { of culture }}{(1 \mathrm{~mL} \text { of culture }+}=\frac{1 \mathrm{~mL} \text { of culture }}{10 \mathrm{~mL} \text { of total volume }}=\frac{1}{10}$

A $1 / 10$ dilution is usually written as $10^{-1}$ (which is called the dilution factor) and is referred to as a 10 -fold dilution. Note that a five-fold dilution is $2 \times 10^{-1}$, whereas a 20 -fold dilution is $5 \times 10^{-2}$.

A clean pipette tip to pipette $0.1 \mathrm{ml}$ as illustrated in Figure 3 of the appropriate suspension onto the agar surface was used. The tube was thumbed before taking the sample. For multiple plates, cells were pipetted into each plate using the same pipette tip and then spread without flaming the spreader between each plate. The spreader was sterilized in 95\% ethanol and then the spreader passed through a flame to ignite the alcohol. The spreader was held carefully until all the alcohol on the spreader completely burned off. The spreader was cooled down by contacting the agar surface.

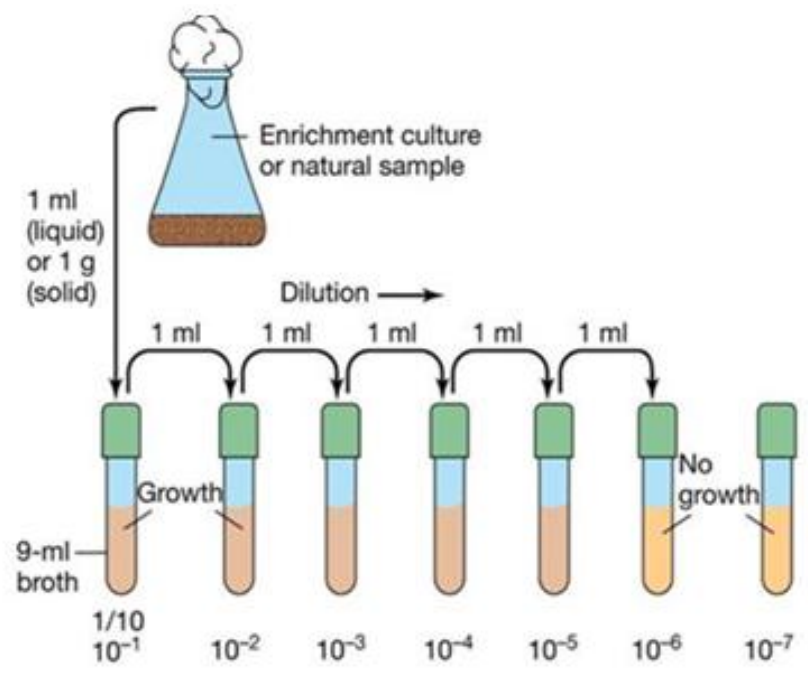

Fig-3: Method of factional dilutions Pasteur's technique.

The flat side was used to spread the suspension over the surface, and then the curved part of the spreader was used to make overlapping strokes. The plate was turned 90 degrees and the process of making overlapping strokes was repeated. The lid was held over the plate to minimize contamination.

\subsection{Microbe Isolation Technique}

Geneticists needing to characterize a bacterial strain require starting with a homogenous population as possible. Therefore, colonies are produced by taking a single bacterial cell and allowing it to multiple into a colony on an agar medium in the laboratory.

All the glassware and loop were sterilized using an autoclave, whilst nutrient agar plates were sterilized using ultraviolet light in the lamina flow. First, the loop was sterilized with the flame and then, a loopful of sample was removed from the mixed culture plate. The sample was then introduced to an agar plate by streaking approximately a third of the plate with the loopful of sample, being careful to not dig into or gouge the agar. This is repeated with additional samples after sterilizing the loop each time until there is a box-like pattern to the streaks within the circular petri dish containing the agar (see Fig-4 for an illustration of the pattern produced). The plate was placed in an incubator at $37^{\circ} \mathrm{C}$ for 24 hours. Growth of microbes was observed and the results were recorded.

\subsection{Samples Storages and Preparation for}

\section{Microbial Analysis}

Samples for microbial analysis were stored in a $-20^{\circ} \mathrm{C}$ freezer (Kendro, Heraeus, Germany).Samples for PCRDGGE analysis was analyzed in dilute liquid form. Freezing temperature was used to assist in disrupting and breaking up samples for better lysis of cells and improving measurements on microbial biomass and activity. 


\subsection{Microbial Analysis}

Microbial DNA that was successfully extracted from the POME sample using methods documented was amplified using PCR technique with the following primer.

\subsection{PCR Amplification of 16s rDNA}

For microbial DNA extracted directly from soil and OPS, extracted DNA was amplified using polymerase chain reaction (PCR).Prior to amplified 16s rDNA, primers used are forward (f) with GC-clamps, 341f (5'-cgc-ccg-ccg-cgcgcg-gcg-ggc-ggg-gcg-ggg-gca-cgg-ggg-gcc-tac-gg-agg-cagcag-3') and reverse (r) primers 907r (5'-ccc-cgt-caa-ttc-atttga-gtt-t-3') [21].

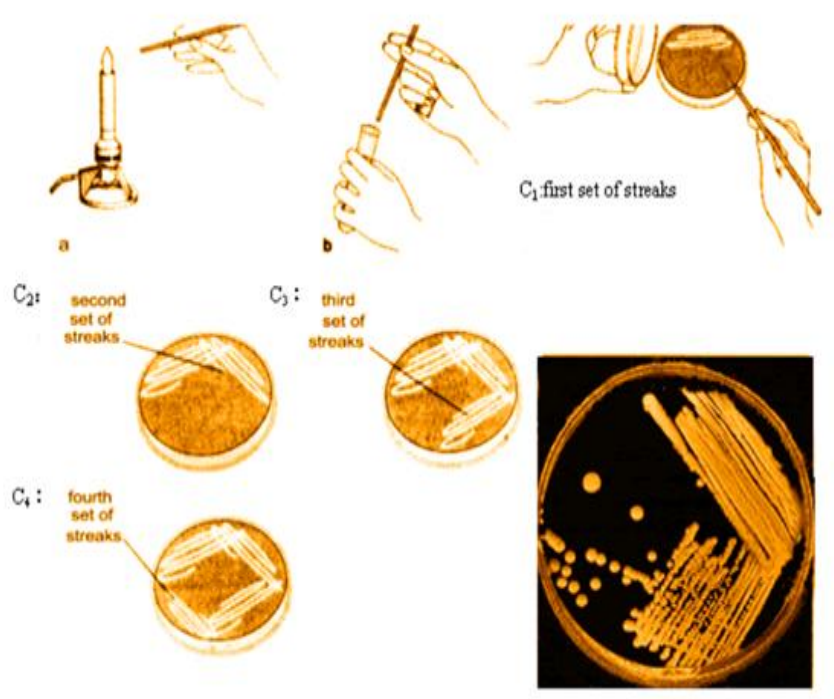

Fig-4: Streak plate techniques

Amplification mixture with these two sets of primers had a final volume of $25 \mathrm{ul}$ and contained $10 \mathrm{pmol}$ of each primer, $100 \mathrm{mMdNTPs}$, 1X PCR buffer, 50mM $\mathrm{Mg}_{2} \mathrm{Cl}, 0.3 \%$ BSA and 2.5 units of Taq polymerase. The reaction began with an initial $94^{\circ} \mathrm{C}$ denaturation for $2 \mathrm{~min}$, followed by 35 cycles of annealing, $94^{\circ} \mathrm{C}$ for $30 \mathrm{~s}, 52.1^{\circ} \mathrm{C}$ for $30 \mathrm{~s}, 72^{\circ} \mathrm{C}$ for $30 \mathrm{~s}$, final extension at $72^{\circ} \mathrm{C}$ for $2 \mathrm{~min}$, then held at $4^{\circ} \mathrm{C}$.

\subsection{Analysis of PCR Products by Denaturing}

\section{Gradient Gel Electrophoresis (DGGE)}

Denaturing Gel Gradient Electrophoresis (DGGE)was conducted in the laboratory according to the method suggested by Muyzer et al. [21].Analysis of PCR products was by Denaturing Gradient Gel Electrophoresis (DGGE).

For microbial extracted DNA directly from the sample, the PCR products were separated on $1.0 \mathrm{mM}$ of $6 \%(\mathrm{w} / \mathrm{v})$ polyacrylamide (37.5:1; acrylamide: bisacrylamide) with a denaturing gradient of $30 \%$ to $60 \%(100 \%$ denaturant corresponds to $7 \mathrm{M}$ urea and $40 \%$ [vol/vol] deionized formamide) for samples from field degradation from Felda Serting Hilir Palm Oil Mill, Serting, Negeri Sembilan, Malaysia. An amount of $30 \mu \mathrm{l} \mathrm{PCR}$ products with $10 \mathrm{ul}$ loading dye was then pipetted into the individual lanes and DGGE was performed at $60^{\circ} \mathrm{C}$ and $60 \mathrm{~V}$ with $1 \mathrm{X}$ TAE buffer for 16 hours (using electrophoresis unit as showed in Fig-5). Gels were stained with a silver stain kit from Bio-Rad (BioRad, USA) for 30 minutes and then rinsed with water and photographed on a UV transillumination table.

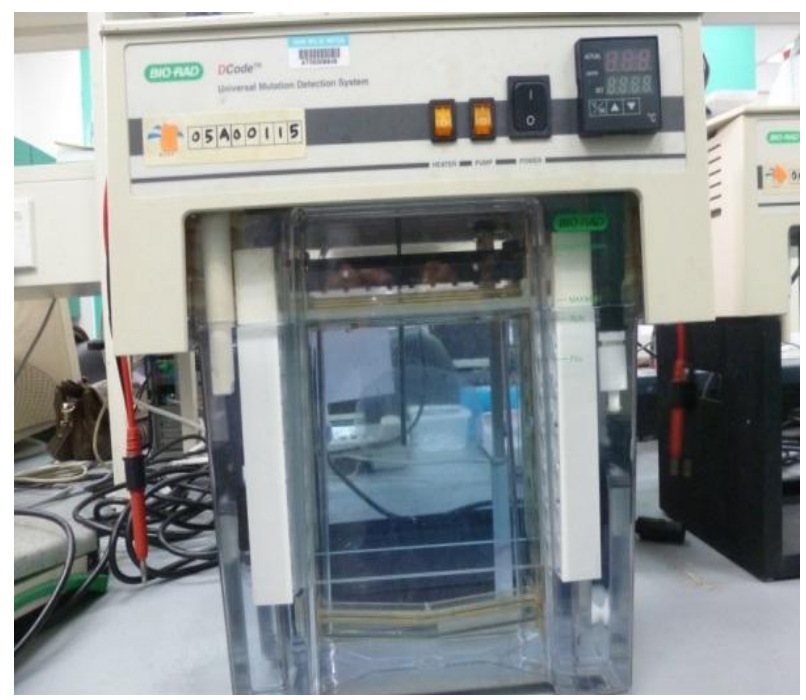

Fig-5: Electrophoresis Unit

\subsection{Recovery of DNA from Agarose and DGGE and}

\section{Purification using QIAquick Gel Extraction Kit}

DNA bands from DGGE were excised with a sterile blade and placed in a $1.5 \mathrm{ml}$ eppendorf tube containing $50 \mu \mathrm{l}$ $\mathrm{ddH}_{2} 0$. Tubes were incubated overnight at $4^{\circ} \mathrm{C}$ to elute the DNA. Eluted DNA was purified using a QIAquick gel extraction kit (QIAGEN, Inc., Valencia, CA). The excisedgel fragment were weighted in a colorless tube and added with 3 volumes of buffer QG to 1 volume of gel (100 $\mathrm{mg} \sim 100 \mu \mathrm{l})$. The gel fragments were incubated at $55^{\circ} \mathrm{C}$ for 10 min (or until the gel slice completely dissolved). The mixture was mixed by vortexing the tube every $2-3 \mathrm{~min}$ during the incubation to help dissolve the gel. After the gel slice dissolved completely, the color of the mixture was checked to see that it is yellow (similar to Buffer QG without dissolved agarose). The mixture of violet (usually for agarose gel) was added with $10 \mu$ of $3 \mathrm{M}$ sodium acetate, pH 5.0 and mixed until the mixture turned yellow. One gel volume of isopropanol was added to the sample and mixed. A QIAquick spin column was placed in a $2 \mathrm{ml}$ collection tube and the sample mixture was applied to the QIAquick column and centrifuged (13,000 rpm)for $1 \mathrm{~min}$. The flow-through was discarded and the QIAquick column was placed in the same collection tube. Five hundred microliters of buffer QG was added to the QIAquick column and centrifuged for $1 \mathrm{~min}$. Seven hundred fifty microliters of buffer PE was added to QIAquick column and centrifuged for $1 \mathrm{~min}$. The QIAquick column was centrifuged for an additional $1 \mathrm{~min}$ to remove any residual ethanol. The DNA was eluted in a clean $1.5 \mathrm{ml}$ micro centrifuge tube, by adding $50 \mu \mathrm{l}$ of buffer EB $(10 \mathrm{mM}$ Tris $\cdot \mathrm{Cl}, \mathrm{pH} 8.5)$ to the center of the QIAquick column membrane and centrifuged for $1 \mathrm{~min}$ at maximum speed. 


\subsection{PCR Amplification of Excised Bands from DGGE}

DNA bands from DGGE gels were excised with a sterile blade and placed in $1.5 \mathrm{ml}$ eppendorf tube containing $50 \mu \mathrm{l}$ deionized water $\left(\mathrm{ddH}_{2} \mathrm{O}\right)$. Tubes were incubated overnight at $4^{\circ} \mathrm{C}$ to elute the DNA. Eluted DNA was purified using QIAquick gel extraction kits (QIAGEN, Inc., Valencia, CA) and was frozen and thawed three times.

Microbial DNA successfully excised and purified from DGGE was amplified using polymerase chain reaction (PCR).Five micro liters of the supernatant were used as a template to re-amplify the DNA using $16 \mathrm{~s}$ rDNA primers,341f (with no GC-clamp) (5'- cct-acg-gga-ggc-agcag-3') and reverse(r) primers 907r (5'-ccc-cgt-caa-ttc-att-tgagtt-t-3'). Amplification was repeated referring to the steps in 'PCR amplification of 16s rDNA'. PCR products from agarose gels were cut and purified using QIAquick Gel Extraction Kit (QIAGEN, Inc., Valencia, CA), which were similar to the purification steps after recovery of DNA from DGGE, and sequenced in both directions with the same primers (with no GC-clamp) as used in PCR.

\subsection{Sequencing Analysis}

Analysis of the experiment was done in triplicate. The PCR products were sent for sequencing to First Base Laboratories Sdn Bhd.When the resulting sequence data was returned, genetic similarity of the partially sequenced $16 \mathrm{~S}$ rRNA genes was searched for in the NCBI Gen-Bank database (http://www.ncbi.nlm.nih.gov/) using the nucleotidenucleotide basic logic alignment search tool (BLAST) to analyse sequence similarity searches on the sequence data to identify the nearest relatives of the partially sequenced $16 \mathrm{~S}$ rRNA genes of excised dominant bands.

\subsection{Phylogenetic Analysis}

The nucleotide sequences determined in this study were aligned and neighbor joining trees were constructed using MEGA version 4.0 (Molecular Evolutionary Genetics Analysis.Neighbour-joining phylogenetic trees were constructed based on the position of the 16S rRNA gene by using the Kimura two-parameter substitution model with complete deletion of gapped positions. The robustness of inferred tree topologies was evaluated by 1,000 bootstrap resamplings of the data, and nodes with bootstrap values $70 \%$ are indicated.

\section{RESULTS AND DISCUSSION}

\subsection{Microbial Community Analysis Using PCR-}

\section{DGGE}

Microorganisms are fundamental to the biological treatment of wastewater [22]. Microorganisms' identification in the SBR in this study was observed by PCR-DGGE analysis in terms of biochemical aspects and bacterial populations. Results indicate that the intensity and position of nucleotide bands only changed modestly as the SBR treatment progressed (Fig-6). This suggests that bacterial colonies did not change markedly throughout SBR treatment [23]. However, each sample showed distinguishable patterns for different bacterial genera or species in each community (Table 2).

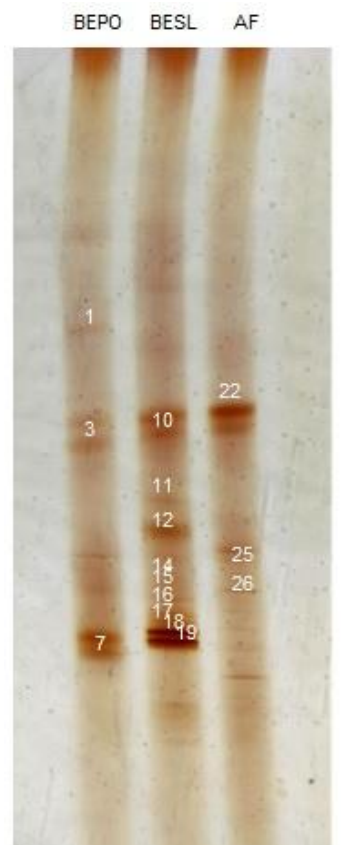

Fig-6: DGGE profile of PCR-amplified 16s rDNA fragments from microbial communities during composting process. Bands 1-31 were excised and sequenced. The arrow indicates the direction of electrophoresis and percentage shows the gradient of DNA denaturants. Indications of the samples BEPO: anaerobic POME, BESL: aerobic treatment and AF: after treatment.

Because DGGE profiles of aerobically digested POME samples were different from initial materials, the bacteria involved in the treatment process did not all come from starting materials (Fig-6). It was shown that different microbial populations from those in the raw material rapidly developed in the SBR process. The shift in microbial population suggested that the bacteria survive in the present of oxygen and can use nutrients in the POME as the growth substrate.

Table-2: The partial 16S rRNA gene sequences of ARC domain and organism with the best-matching sequences determined by BLAST searches.

\begin{tabular}{|c|c|c|c|c|}
\hline $\begin{array}{c}\text { NCBI BLAST and } \\
\text { Closest Identity in } \\
\text { GenBank }\end{array}$ & $\begin{array}{l}\text { Strain } \\
\text { Name }\end{array}$ & $\begin{array}{c}\text { DGGE } \\
\text { Band }\end{array}$ & $\begin{array}{l}\text { Simi- } \\
\text { larity } \\
(\%)\end{array}$ & $\begin{array}{l}\text { Acces- } \\
\text { sion No }\end{array}$ \\
\hline $\begin{array}{l}\text { Bacillus subtilis } \\
\text { strain Rhizo-03 }\end{array}$ & $\mathrm{AF} 1$ & 1 & 99 & $\begin{array}{c}\text { KF0155 } \\
16\end{array}$ \\
\hline \multirow{2}{*}{$\begin{array}{c}\text { Caldanaerobius sp. } \\
\text { CT2503_005 }\end{array}$} & BE3 & 3 & 99 & \multirow{2}{*}{$\begin{array}{c}\text { JX9849 } \\
80\end{array}$} \\
\hline & BE7 & 7 & 99 & \\
\hline \multirow{5}{*}{$\begin{array}{c}\text { Rummeliibacillus } \\
\text { suwonensis strain } \\
\text { G20 }\end{array}$} & BE10 & 10 & 100 & \multirow{5}{*}{$\begin{array}{c}\text { NR1097 } \\
49\end{array}$} \\
\hline & BE11 & 11 & 100 & \\
\hline & BE12 & 12 & 100 & \\
\hline & BE15 & 15 & 100 & \\
\hline & BE16 & 16 & 100 & \\
\hline
\end{tabular}




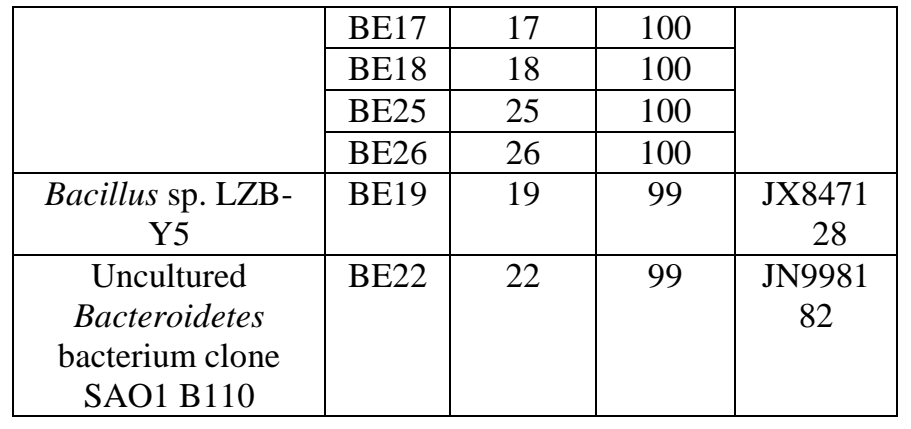

The NCBI-BLAST identified in each bacterium is presented in Table-3 and Fig-7. These results are consistent with the phylum assignment data and that prominent members were mainly uncultured and unidentified bacteria.
The recovered sequences from major bands were distributed unevenly among 3 phylogenetic groupings: 16 sequences of Firmicutes (the most predominant phylum), 5 sequence of Proteobacterium (the second largest phylum) and 2 sequences of Bacteroidetes (the third most predominant phylum) (Fig-6). In this study, the phylum of Firmicutes, the closest to Lactobacillus, was the only prominent detected in POME (Table-3). This result could be attributed to the remaining oil content in the anaerobically digested POME as wastewater treatment used in this research. In the presence of oil, lactic acid bacteria become the major strain of micro flora [24]. The uncultured bacterium clone clone SAO1 B110 (JN998182) (Table-7) detected in thisstudy has been found in POME (anaerobic pond) it was dominated by the members of the phylum Bacteroidetes (uncultured biogas bacterium) [23]. The sample taken for analyze at

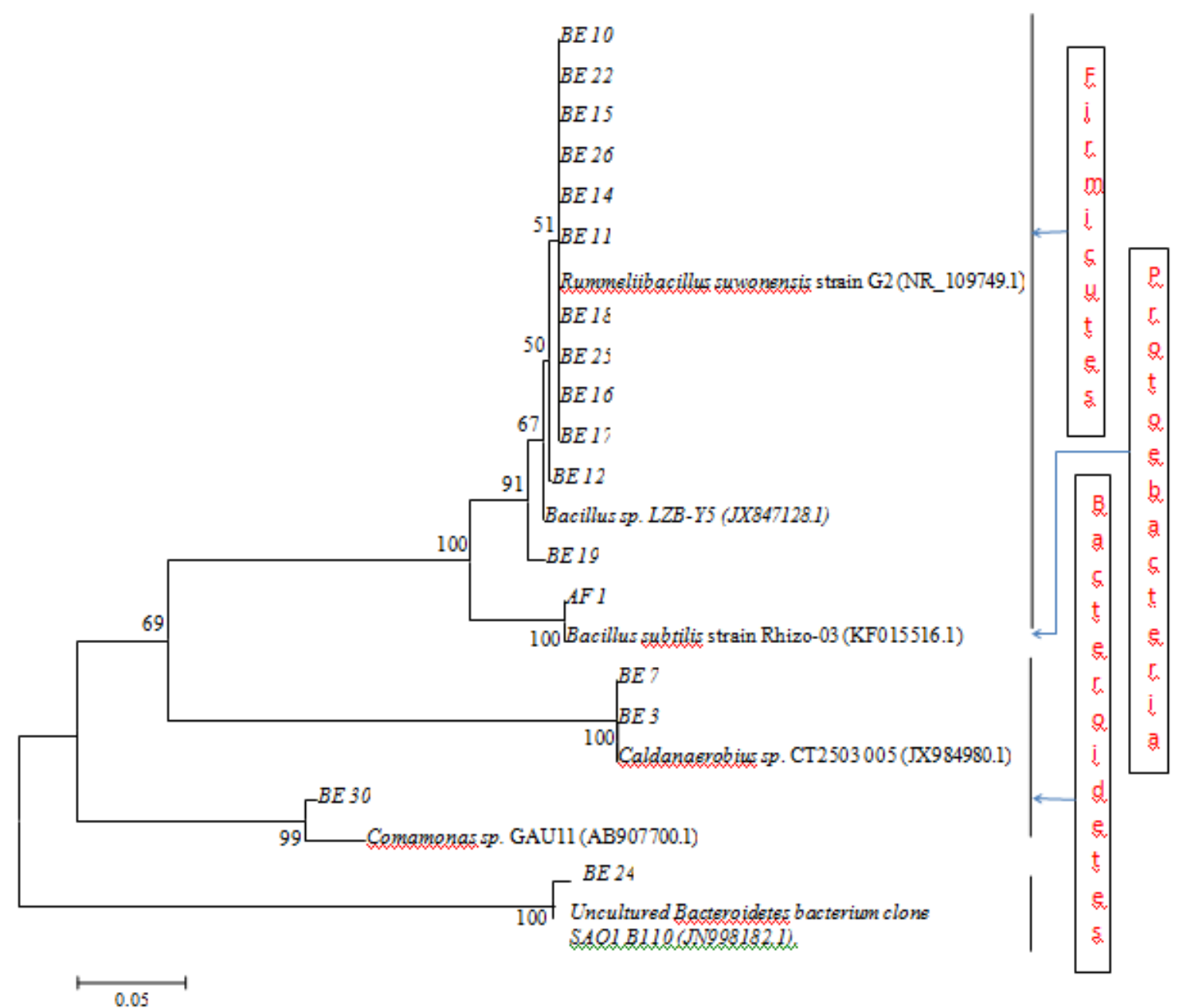

Fig-7: Phylogenetic relationship analysis between 16s rRNA gene of PCR-DGGE and related bacteria from gene database using neighbour-joining method. The bar $=0.05$ substitutions per nucleotide position. Bootstrap values at nodes are percentages based on estimation of 100 trees.

point before SBR treatment start has the characteristic of anaerobic wastewater POME resulted in Caldanaerobius sp. CT2503_005 was isolated at band shown BE3 and BE7 in Table-3 .This type of species is an obligate anaerobic, sporeforming, Gram-type-positive but Gram-staining-negative thermophilic bacterium [25].
Sequence closely related to Rummeliibacillus suwonensis strain $G 20$ was detected grows during SBR treatment at band BE10, BE11, BE12, BE15, BE16, BE17 and BE18. Meanwhile BE25 and BE26 were found at band after SBR treatment process done. Rummeliibacillus suwonensis is an aerobic, Gram-positive, rod shaped, round-spore-forming 
bacteria which were isolated from aerobic condition [26]. This bacterium was indigenous to sludge although it was initially present at very minor population and almost undetectable in the starting part of the treatment. It have been reported that Rummeliibacillus spp. was involved in wastewater treatment such as textile effluent [27]. It has also been found in the fermentation process of batch brewing of Chinese liquor and in traditional salted and fermented food [28, and 29].

In this study, sequence related to Bacillus subtilisRhizo-03 strain was found to be dominated in the starting material of the treatment. It has been demonstrated previously that Bacillus subtilis strain Rhizo-03 is capable of reducing wastewater under anaerobic conditions [30]. That is why this bacteria found at stage before SBR treatment was completed at band AF1 shown in Fig-6, whereby the conditions of treated anaerobic POME wastewater is in anaerobic condition.

\section{CONCLUSION}

At present, the vast development of molecular analysis technologies and techniques gives researchers the ability to study complex communities of microbes and link them to process performance. In that light, the study conducted here was an effort to understand microbial community structures within activated sludge samples placed in a small batch reactor and compare it with communities in activated sludge with an aerobic treatment unit, anaerobic POME wastewater, and extremely minimized sludge wasting finally from the activated sludge. Identification of major bacterial species and each system were analysed with PCR-DGGE. Bacteria species that were identified were placed within a phylogenetic tree found in the SBR process.

There were several conclusions obtained from the investigation of the long and short term effects of microorganism on reactor performance: PCR-DGGE was used to study the isolated microorganisms that play an important role in the biodegradation of the pollutants in the anaerobic POME wastewater and was later identified using NCBI-BLAST. In anaerobic POME wastewater, 6 sequences of Firmicutes (the most predominant phylum), 5 sequence of Proteobacterium (the second largest phylum) and 2 sequences of Bacteroidetes (the third most predominant phylum) were found through DGGE results.

\section{REFERENCES}

[1]. Verdier, T., Coutand, M., Bertron, A., and Roques, C. (2014). A review of indoor microbial growth across building materials and sampling and analysis methods. Building and Environment.80: 136-149.

[2]. Saifuddin, N., and Dinara, S. (2011). Pretreatment of palm oil mill effluent (POME) using magnetic chitosan. Journal of Chemistry. 8(S1): S67-S78.

[3]. Ren, L., Wu, Y., Ren, N., Zhang, K., and Xing, D. (2010). Microbial community structure in an integrated A/O reactor treating diluted livestock wastewater during start-up period. Journal of Environmental Sciences. 22(5): 656-662.
[4]. Girvan, M. S., Campbell, C. D., Killham, K., Prosser, J. I., and Glover, L. A. (2005). Bacterial diversity promotes community stability and functional resilience after perturbation. Environmental Microbiology. 7(3): 301-313.

[5]. Nachaiyasit, S., and Stuckey, D. C. (1997). The effect of shock loads on the performance of an anaerobic baffled reactor (ABR). 1. Step changes in feed concentration at constant retention time. Water Research. 31(11): 2737-2746. [6]. Torkian, A., Eqbali, A., and Hashemian, S. J. (2003). The effect of organic loading rate on the performance of UASB reactor treating slaughterhouse effluent. Resources, Conservation and Recycling. 40(1): 1-11.

[7]. Chelliapan, S., Wilby, T., and Sallis, P. J. (2006). Performance of an up-flow anaerobic stage reactor (UASR) in the treatment of pharmaceutical wastewater containing macrolide antibiotics. Water Research. 40(3): 507-516.

[8]. Fang, C., Sompong, O., Boe, K., and Angelidaki, I. (2011). Comparison of UASB and EGSB reactors performance, for treatment of raw and deoiled palm oil mill effluent (POME). Journal of Hazardous Materials. 189(1): 229-234.

[9]. Fernández, A., Huang, S., Seston, S., Xing, J., Hickey, R., Criddle, C., and Tiedje, J. (1999). How stable is stable? Function versus community composition. Applied and Environmental Microbiology. 65(8): 3697-3704.

[10]. Akarsubasi, A. T., Ince, O., Kirdar, B., Oz, N. A., Orhon, D., Curtis, T. P., Head, I. M., and Ince, B. K. (2005). Effect of wastewater composition on archaeal population diversity. Water Research. 39(8): 1576-1584.

[11]. Bialek, K., Kim, J., Lee, C., Collins, G., Mahony, T., and O'Flaherty, V. (2011). Quantitative and qualitative analyses of methanogenic community development in highrate anaerobic bioreactors. Water Research. 45 (3): 12981308.

[12]. Fernandez, A. S., Hashsham, S. A., Dollhopf, S. L., Raskin, L., Glagoleva, O., Dazzo, F. B., Hickey, R. F., Criddle, C. S., and Tiedje, J. M. (2000). Flexible community structure correlates with stable community function in methanogenic bioreactor communities perturbed by glucose. Applied and Environmental Microbiology. 66(9): 40584067.

[13]. Saratale, R. G., Saratale, G. D., Chang, J. S., and Govindwar, S. P. (2011). Bacterial decolorization and degradation of azo dyes: a review. Journal of the Taiwan Institute of Chemical Engineers. 42(1): 138-157.

[14]. Solís, M., Solís, A., Pérez, H. I., Manjarrez, N., and Flores, M. (2012). Microbial decolouration of azo dyes: a review. Process Biochemistry. 47(12): 1723-1748.

[15]. Senan, R. C., and Abraham, T. E. (2004). Bioremediation of textile azo dyes by aerobic bacterial consortium aerobic degradation of selected azo dyes by bacterial consortium. Biodegradation. 15(4): 275-280.

[16]. Dafale, N., Rao, N. N., Meshram, S. U., and Wate, S. R. (2008). Decolorization of azo dyes and simulated dye bath wastewater using acclimatized microbial consortiumbiostimulation and halo tolerance. Bioresource Technology. 99(7): 2552-2558. 
[17]. Mikesková, H., Novotný, Č., and Svobodová, K. (2012). Interspecific interactions in mixed microbial cultures in a biodegradation perspective. Applied Microbiology and Biotechnology. 95(4): 861-870.

[18]. Desai, C., Jain, K., Patel, B., and Madamwar, D. (2009). Efficacy of bacterial consortium-AIE2 for contemporaneous $\mathrm{Cr}(\mathrm{VI})$ and azo dye bioremediation in batch and continuous bioreactor systems, monitoring steadystate bacterial dynamics using qPCR assays. Biodegradation. 20(6): 813-826.

[19]. Moosvi, S., Keharia, H., and Madamwar, D. (2005). Decolourization of textile dye Reactive Violet 5 by a newly isolated bacterial consortium RVM 11.1. World Journal of Microbiology and Biotechnology. 21(5): 667-672.

[20]. Muyzer, G., De Waal, E. C., and Uitterlinden, A. G. (1993). Profiling of complex microbial populations by denaturing gradient gel electrophoresis analysis of polymerase chain reaction-amplified genes coding for $16 \mathrm{~S}$ rRNA. Applied and Environmental Microbiology. 59(3): 695-700.

[21]. Ivorra, N., Barranguet, C., Jonker, M., Kraak, M. H., and Admiraal, W. (2002). Metal-induced tolerance in the freshwater microbenthic diatom Gomphonema parvulum. Environmental Pollution. 116(1): 147-157.

[22]. Baharuddin, A. S., Kazunori, N., Abd-Aziz, S., Tabatabaei, M., Abdul Rahman, N. A., Hassan, M. A., Wakisaka, M., Sakai, K., and Shirai, Y. (2009). Characteristics and microbial succession in co-composting of oil palm empty fruit bunch and partially treated palm oil mill effluent. Open Biotechnoloy Journal.3: 92-100.

[23]. Hemmi, H., Shimoyama, T., Nakayama, T., Hoshi, K., and Nishino, T. (2004). Molecular biological analysis of microflora in a garbage treatment process under thermoacidophilic conditions. Journal of Bioscience and Bioengineering. 97(2): 119-126.

[24]. Lee, Y. J., Mackie, R. I., Cann, I. K., and Wiegel, J. (2008). Description of Caldanaerobius Fijiensis gen. nov., sp. nov., an Inulin-degrading, Ethanol-producing, Thermophilic Bacterium from a Fijian Hot Spring Sediment, and Reclassification of Thermoanaerobacterium polysaccharolyticum and Thermoanaerobacterium zeae as Caldanaerobius Polysaccharolyticus comb. nov. and Caldanaerobius zeae comb. nov. International Journal of Systematic and Evolutionary Microbiology. 58(3): 666-670. [25]. Vaishampayan, P., Miyashita, M., Ohnishi, A., Satomi, M., Rooney, A., La Duc, M. T., and Venkateswaran, K. (2009). Description of Rummeliibacillus stabekisii gen. nov., sp. nov. and reclassification of Bacillus pycnus Nakamura et al. 2002 as Rummeliibacillus pycnus comb. nov. International Journal of Systematic and Evolutionary Microbiology. 59(5): 1094-1099.

[26]. Cherukupalle Bhuvaneswar, Gunduluru swathi, Baki VijayaBhaskar,Tirumalasetty Munichandrababu,Wudayagiri Rajendra (2012).Effective Synergetic Biodegradation of Diesel oil by Bacteria.International Journal of Environmental Biology; 2(4): 195-199.

[27]. Wang Xiuheng*, Zhang Kun, Ren Nanqi, Li Nan, Ren Lijiao. (2009). Monitoring microbial community structure and succession of an A/O SBR during start-up period using
PCR-DGGE.Journal Of Environmental Sciences21 : 223228.

[28]. Luo Hui-Bo,Hou Hai-Bo,Huang Zhi-Guo,Wei ChunHui,Ye Guang-Bin (2011) Optimization of PCR-DGGE Electrophoresis Conditions of Eucaryotic Microorganisms Community in Daqu.Journal of Sichuan University of Science \& Engineering-05.

[29]. Horitsu, H., Takada, M., Idaka, E., Tomoyeda, M., and Ogawa, T. (1977). Degradation of p-Aminoazobenzene by Bacillus subtilis. European Journal of Applied Microbiology and Biotechnology.4(3): 217-224.

\section{BIOGRAPHIES}

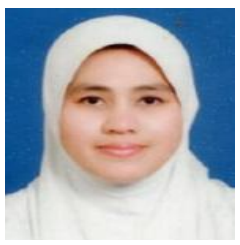

Husna Ahmad Tajuddin is at final stage of Ph.D at Department of Chemical and Environmental Engineering, University Putra Malaysia (UPM), Malaysia.

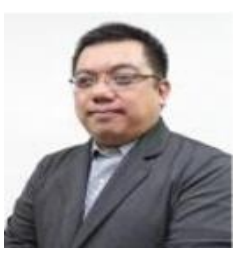

Prof. Dr. Luqman Chuah Abdullah is a Professor at Department of Chemical and Environmental Engineering, University Putra Malaysia (UPM), Malaysia.

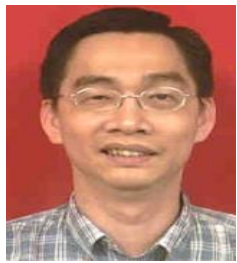

Prof. Dr. Thomas Choong Shean Yaw is a Professor at Department of Chemical and Environmental Engineering, University Putra Malaysia (UPM), Malaysia. 